Rev. Bras. Saúde Prod. Anim., Salvador, v.16, n.3, p.499-512 jul./set.., 2015 http://www.rbspa.ufba.br

\title{
Implantação de pastagens sob sistema monocultivo e integrado com lavoura utilizando biofertilizante de cama de aviário como adubação de cobertura
}

\author{
Establishment of pastures under monoculture farming and integrated with biofertilizer \\ using poultry litter as a nutrient source
}

\author{
SILVEIRA JUNIOR, Otacilio ${ }^{1 *}$; SANTOS, Antônio Clementino dos ${ }^{2}$; ROCHA, José \\ Mario Lopes ${ }^{1}$; FERREIRA, Caio Leonardo Silva ${ }^{1}$; OLIVEIRA, Leonardo Bernardes \\ Taverny de ${ }^{1}$; RODRIGUES, Marcos Odilon Dias ${ }^{1}$; RODRIGUES, Márcio Odilon Dias ${ }^{1}$
}

\footnotetext{
${ }^{1}$ Universidade Federal de Tocantins, Programa de Pós-Graduação em Ciência Animal Tropical, Araguaína, Tocantins, Brasil.

${ }^{2}$ Universidade Federal de Tocantins, Escola de Medicina Veterinária e Zootecnia, Araguaína, Tocantins, Brasil.

*Endereço para correspondência: otaciliosilveira@hotmail.com
}

\section{RESUMO}

Objetivou-se avaliar o efeito da utilização de biofertilizante obtido através da biodigestão anaeróbica da cama de aviário nas características produtivas do capim Piatã, e nas características químicas do solo. Avaliou-se cinco doses de biofertilizantes $\left(0 ; 10 ; 20 ; 30 ; 40 \mathrm{~m}^{3} \cdot \mathrm{ha}^{-1}\right)$ em dois sistemas de cultivos (sistema monocultivo de capim Piatã e sistema consorciado de capim Piatã com sorgo forrageiro hibrido BRS 610). Foram verificadas as características agronômicas e estruturais submetidas às doses de biofertilizante nos dois sistemas de cultivos, verificado também a influência do biofertilizante nas características químicas do solo. Os dois sistemas de produção responderam de forma eficiente com a aplicação do biofertilizante, porém o colmo e o perfilhamento foram os principais componentes responsáveis pelo aumento de produtividade. As doses de biofertilizante trouxeram incrementos nas características químicas do solo, sendo identificado diferença apenas para $\mathrm{K}^{+}$e matéria orgânica entre os sistemas de cultivos, evidenciando o sistema consorciado com as maiores extrações de nutrientes do solo pelas culturas. $\mathrm{O}$ biofertilizante mostrou ser satisfatório considerando incrementos obtidos na produção de forragem, no número de perfilho, área foliar, massa por perfilho sendo boa opção para melhoria da produtividade do capim Piatã, respondendo de forma positiva nos dois sistemas de produção.

Palavras-chave: adubação orgânica, Brachiaria brizantha cv. Piatã, integração lavoura pecuária, Sorghum bicolor

\section{SUMMARY}

The objective was to evaluate the effect of the use of bio-fertilizers obtained by anaerobic biodigestion Aviary bed productive characteristics of Piatã, grass and soil chemical characteristics. Assessed five doses of biofertilizers $(0 ; 10 ; 20 ; 30$; $40 \mathrm{~m}^{3}$. $\left.\mathrm{Ha}^{-1}\right)$ in two cultivation systems (monoculture system of Piatã grass and grass intercropping system with hybrid forage sorghum Piatã BRS 610). Agronomic characteristics were verified and submitted to structural measures of biofertilizer in the two systems of crops, checked also the influence of biofertilizer in soil chemical characteristics. The two production systems responded efficiently with the application of biofertilizer, however the thatched roofs and tilling was the main components responsible for increased productivity. The doses of biofertilizer brought chemical soil characteristics increments, being identified only difference to $\mathrm{K}^{+}$and organic matter between systems of crops, evidencing the Member with the highest extraction system of soil nutrients by crops. The biofertilizer proved satisfactory considering increments obtained in the production of fodder, in tiller number, leaf area, mass per tiller being good option for improving the productivity of grass Piatã, responding positively in both production systems.

Keywords: Brachiaria brizanthacv. Piatã, croplivestock integration systems, organic fertilizer, Sorghum bicolor 
Rev. Bras. Saúde Prod. Anim., Salvador, v.16, n.3, p.499-512 jul./set.., 2015 http://www.rbspa.ufba.br

\section{INTRODUÇÃO}

A produtividade é a principal característica almejada nos diversos sistemas de produção agropecuária. Buscando de forma racional o aumento produtivo com o mínimo de insumos gastos e com a máxima eficiência. Para isso, deve-se maximizar o uso da terra de forma a obter melhores produções por área, porem de baixo custo e que cause baixos impactos ambientais (BALBINO et al., 2011).

Uma opção que favorece a maximização do uso da terra é o sistema de integração lavoura-pecuária, que ajuda a minimizar os custos para renovação das pastagens. $O$ sistema que integra culturas produtoras de grãos e forrageiras vêm sendo destaque na pecuária, pois aproveita ao máximo os recursos do solo, o que contribui para reduzir os custos de implantação e manutenção das culturas, fazendo assim a pastagem aproveitar do aumento da matéria orgânico no solo e aproveitamento da adubação residual utilizado na cultura anual, favorecendo melhorias nas condições químicas, físicas e biológicas do solo (PARIZ et al., 2009).

Com a contribuição do sistema de integração é preciso que os produtores tenham novas alternativas viáveis que possam substituir ou reduzir o uso de fertilizantes químicos. Uma vez que os fertilizantes é um dos principais responsáveis pelo custo de produção, sendo estes de fontes não renováveis. Uma alternativa favorável são os resíduos orgânicos, em destaques os biofertilizantes, os quais apresentam em sua composição nutrientes na forma orgânica e inorgânica, tornando excelente fonte de adubação, contendo na sua composição a maioria dos nutrientes essenciais às plantas (ARAÚJO et al., 2008).
A matéria prima para produção de biofertilizante com alta disponibilidade de nutrientes é a cama de aviário, que apresenta os principais nutrientes (nitrogênio, cálcio, fósforo, potássio, magnésio) em concentrações adequadas para atender o desenvolvimento das plantas e com o processo de biodigestão torna boa parte desses nutrientes prontamente disponíveis, favorecendo a sua utilização como fonte de nutrientes de rápida disponibilidade, além disso, a cama de aviário é de fácil obtenção e de baixo custo.

O objetivo deste estudo foi avaliar o efeito do biofertilizante de cama de aviário, na produtividade da Brachiaria brizantha cv Piatã em sistema de produção consorciado com sorgo forrageiro (BR 610) e em monocultivo, além de verificar os efeitos nas características químicas do solo.

\section{MATERIAL E MÉTODOS}

O trabalho foi realizado no município de Araguaína - Tocantins, na Universidade Federal do Tocantins, no ano de 2012. A área experimental foi localizada nas seguintes coordenadas geográficas: $7^{\circ} 13^{\prime} 48^{\prime \prime} \mathrm{S}$ e $48^{\circ} 14^{\prime} 17^{\prime \prime} \mathrm{O}$. $\mathrm{O}$ clima da região é classificado como AW (quente e úmido), com estação bem definida, apresentando precipitação pluviométrica média anual de $1800 \mathrm{~mm}$ e temperatura média anual de $25^{\circ} \mathrm{C}$. Os dados de precipitação e temperatura máxima e mínima durante o período experimental são apresentados na Tabela 1.

O solo da área é classificado como Neossolo Quartzarênico Órtico típico. Antes da implantação do experimento, foi realizada amostragens do solo da área para verificação das características químicas do solo (Tabela 2), e para 
Rev. Bras. Saúde Prod. Anim., Salvador, v.16, n.3, p.499-512 jul./set.., 2015 http://www.rbspa.ufba.br ISSN 15199940

realização da correção do solo (Aplicação de 1 Ton ha $^{-1}$ de calcário dolomítico PRNT >90\%).

$\mathrm{O}$ experimento foi realizado em delineamento blocos casualizados, com parcelas subdividida, caracterizado por parcelas as doses de biofertilizante e a subparcela os sistemas de cultivo. As parcelas consisti em cinco doses de

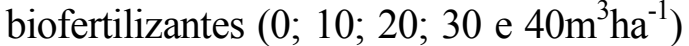
e a subparcela em dois sistemas de cultivo (Brachiaria brizantha cv. Piatã em consórcio com sorgo forrageiro e Brachiaria brizantha cv. Piatã em monocultivo), totalizando dez tratamentos com quatro repetições cada, perfazendo 40 parcelas de $10 \mathrm{~m}^{2}(4 \times 2,5 \mathrm{~m})$.

Tabela 1. Comportamento termo pluviométrico de Araguaína no período de janeiro a julho de 2012

\begin{tabular}{lccccccc}
\hline Descrição & Janeiro & Fevereiro & Março & Abril & Maio & Junho & Julho \\
\hline Precipitação $(\mathrm{mm})$ & 306,1 & 256,1 & 170,1 & 42,7 & 76,3 & 28,8 & 20,5 \\
Temp. Máx. $\left({ }^{\circ} \mathrm{C}\right)$ & 29,7 & 30,0 & 31,1 & 32,0 & 32,4 & 33,00 & 34,1 \\
Temp. Mín. $\left({ }^{\circ} \mathrm{C}\right)$ & 21,2 & 20,3 & 20,8 & 20,7 & 19,6 & 18,5 & 16,5 \\
\hline
\end{tabular}

Tabela 2. Características químicas do solo da área experimental antes da implantação do experimento, na camada de $0-15 \mathrm{~cm}$ de profundidade

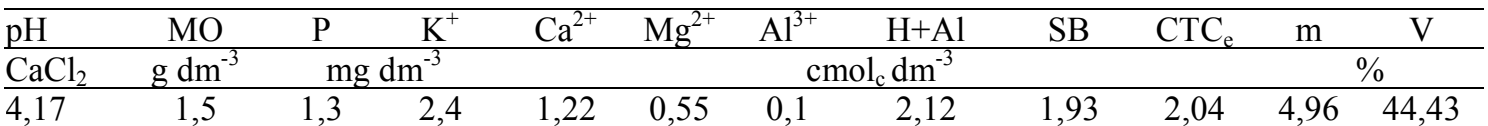

$\mathrm{SB}=$ Soma de Bases; $\mathrm{MO}=$ Matéria orgânica; $\mathrm{CTC}_{\mathrm{e}}=$ Capacidade de troca catiônica efetiva; $\mathrm{m}=$ Saturação por alumínio; V = Saturação por base.

$\mathrm{Na}$ implantação do experimento foi realizado gradagem leve e posterior adubação com $30 \mathrm{~kg} \mathrm{ha}^{-1}$ de N; $30 \mathrm{~kg} \mathrm{ha}^{-1}$ de $\mathrm{P}_{2} \mathrm{O}_{5}$ e $30 \mathrm{~kg} \mathrm{ha}^{-1}$ de $\mathrm{K}_{2} \mathrm{O}$ na forma de ureia, superfosfato simples e cloreto de potássio, respectivamente, sendo realizada a aplicação dos adubos em linhas junto com a semeadura do capim Piatã e do sorgo forrageiro (BRS 610). No sistema consorciado a semeadura do sorgo foi realizada em linhas com espaçamentos de $0,5 \mathrm{~m}$ e entre as linhas do sorgo foram implantadas mais duas linhas adicionais com capim Piatã. No sistema em monocultivo o capim Piatã foi semeado em linhas usando mesmo espaçamento do sistema consorciado, sendo quatro linhas de capim em $0,5 \mathrm{~m}$. $\mathrm{O}$ biofertilizante foi produzido em três tonéis de $1 \mathrm{~m}^{3}$ lacrado, usando cama de aviário de aves a ser direcionadas para postura, sendo usada como matéria prima para a cama das aves palha de arroz. Foi utilizada proporção de 1:3 de cama de aviário e água, ou seja, $1 \mathrm{~kg}$ de cama (Matéria Natural) para 3kg de água, o material ficou nos tonéis por 65 dias. As doses de biofertilizante foram aplicadas aos 25 e 44 dias após germinação das sementes, sendo realizadas as aplicações em linhas, próxima a linha da semeadura, usando regadores de 10L, os resultados da análise química do biofertilizante apresenta-se na Tabela 3.

A cada 28 dias foram realizados ciclos de coletas de forragem (Fevereiro a Junho de 2012) para mensuração dos atributos agronômicos e estruturais, avaliando: altura $(\mathrm{cm})$, produção de massa seca total (MST em Ton $\mathrm{ha}^{-1}$ ) e a proporção dos 
Rev. Bras. Saúde Prod. Anim., Salvador, v.16, n.3, p.499-512 jul./set.., 2015 http://www.rbspa.ufba.br

componentes morfológicos lâmina foliar (\%), colmo mais bainha foliar (\%), material morto (\%), relação folha:colmo $(\mathrm{F}: \mathrm{C})$, índice de área foliar (IAF), densidade volumétrica $\left(\mathrm{kg} \mathrm{cm} \mathrm{cm}^{-1}\right.$ de MS), número de perfilho (Unid $\mathrm{m}^{-2}$ ) $\mathrm{e}$ massa por perfilho $\left(\mathrm{g} \mathrm{unid}^{-1}\right)$.

Para verificação da eficiência do sistema consorciado foi verificado o índice de equivalência de área (IEA) nas diferentes doses de biofertilizante testadas: sendo calculado conforme proposto por Willey (1979), onde é definido como a área relativa de terra, em sistema de monocultivo, necessária para ter os mesmos rendimentos que o cultivo consorciado. O seu cálculo é feito pela seguinte fórmula: IEA = $\mathrm{S}_{\mathrm{C}} / \mathrm{S}_{\mathrm{m}}+\mathrm{C}_{\mathrm{C}} / \mathrm{C}_{\mathrm{m}}$, onde $\mathrm{S}_{\mathrm{C}}$ e $\mathrm{C}_{\mathrm{C}}$ são os rendimentos de massa seca do sorgo e capim Piatã consorciados, e $\mathrm{M}_{\mathrm{m}}$ e $\mathrm{C}_{\mathrm{m}}$ são os rendimentos do sorgo e do capim Piatã em monocultivo.

Tabela 3. Características químicas do biofertilizante de cama de aviário e valores equivalentes de nutrientes de acordo com as devidas doses de aplicação

\begin{tabular}{|c|c|c|c|c|c|c|c|c|c|}
\hline \multirow{2}{*}{ Aplicação } & $\mathrm{N}$ & $\mathrm{P}_{2} \mathrm{O}_{5 \text { total }}$ & $\mathrm{K}_{2} \mathrm{O}_{\text {solúvel }}$ & $\mathrm{Ca}$ & $\mathrm{Mg}$ & MO* & Umid** & $\mathrm{MM}^{* * *}$ & $\mathrm{Na}$ \\
\hline & \multicolumn{9}{|c|}{$\%$} \\
\hline $1^{\circ}$ & 0,51 & 0,07 & 0,48 & 0,29 & 0,10 & 5,50 & 91 & 3,50 & 0,064 \\
\hline $2^{\circ}$ & 0,49 & 0,06 & 0,47 & 0,27 & 0,07 & 4,00 & 93 & 3,00 & 0,062 \\
\hline Doses & \multicolumn{9}{|c|}{ Kg.ha $^{-1}$} \\
\hline $10 \mathrm{~m}^{3} \mathrm{ha}^{-1}$ & 50 & 6,5 & 47,5 & 28,0 & 8,5 & - & - & - & 6,3 \\
\hline $20 \mathrm{~m}^{3} \mathrm{ha}^{-1}$ & 100 & 13,0 & 95,0 & 56,0 & 17,0 & - & - & - & 12,6 \\
\hline $30 \mathrm{~m}^{3} \mathrm{ha}^{-1}$ & 150 & 19,5 & 142,5 & 84,0 & 25,5 & - & - & - & 18,9 \\
\hline $40 \mathrm{~m}^{3} \mathrm{ha}^{-1}$ & 200 & 26,0 & 190,0 & 112,0 & 34,0 & - & - & - & 25,3 \\
\hline
\end{tabular}

Fonte: Análise realizada pelo laboratório Zoofértil, Palmas-TO, *Mat. Orgânica, **Umidade, ***Mat. Mineral.

As coletas de solo foram realizadas nas camadas de $0-7 \mathrm{~cm}$ e $7-15 \mathrm{~cm}$ de profundidade. As avaliações químicas do solo realizadas foram: potencial Hidrogeniônico ( $\mathrm{pH}$ em $\mathrm{CaCl}_{2}$ ), Fósforo melich $\left(\mathrm{P} \mathrm{mg} \mathrm{dm}{ }^{-3}\right)$, Potássio $\left(\mathrm{K}^{+} \mathrm{mg}\right.$ $\left.\mathrm{dm}^{-3}\right)$, Cálcio $\left(\mathrm{Ca}^{2+} \mathrm{cmol}_{\mathrm{c}} \mathrm{dm}^{-3}\right)$, Magnésio $\left(\mathrm{Mg}^{2+} \mathrm{cmol}_{\mathrm{c}} \mathrm{dm}^{-3}\right)$, Alumínio $\left(\mathrm{Al}^{3+} \mathrm{cmol}_{\mathrm{c}} \mathrm{dm}^{-3}\right)$, soma de bases (SB $\mathrm{cmol}_{\mathrm{c}} \mathrm{dm}^{-3}$ ), capacidade de troca catiônica efetiva $\left(\mathrm{CTC}_{\mathrm{e}} \mathrm{cmol}_{\mathrm{c}} \mathrm{dm}^{-3}\right)$, saturação por alumínio (m \%) e matéria orgânica ( $\mathrm{MO} \mathrm{g} \mathrm{dm}{ }^{-3}$ ).

As variáveis analisadas foram submetidas ao teste de normalidade (Teste de Kolmogorov-Smirnov) e homocedasticidade (Teste de Cochran) para verificação da distribuição dos dados, se apresentava distribuição normal e homogeneidade. As variáveis que apresentaram normalidade e homocedasticidade foram realizadas análise de variância, sendo as respostas submetidas a teste de regressão. A escolha da equação foi realizada com base no coeficiente de determinação, na significância da regressão e de seus coeficientes testados ao nível de 5\% de probabilidade. As características químicas do solo foram submetidas teste de média em parcela subdivida, comparadas pelo teste de Tukey ao nível de 5\% de significância.

\section{RESULTADOS E DISCUSSÃO}

Não foi evidenciada interação ciclos de pastejo com doses de biofertilizante 
Rev. Bras. Saúde Prod. Anim., Salvador, v.16, n.3, p.499-512 jul./set.., 2015 http://www.rbspa.ufba.br ISSN 15199940

$(\mathrm{P}>0,05)$ para nenhuma das variáveis agronômicas e estruturais avaliadas, permitindo assim a análise dos dados em conjunto, no entanto para o sistema de cultivo e doses de biofertilizante apresentou interação $(\mathrm{P}<0,01)$ para as variáveis IAF e Densidade volumétrica. A produção de forragem (Figura 1a) apresentou efeito linear com a aplicação de biofertilizante para os dois sistemas de cultivos, o que proporcionou nas maiores dozes aplicada de biofertilizante produção semelhante. O sistema consorciado apresentou melhor eficiência com aplicação do biofertilizante, sendo relacionada ao incremento no IAF e na altura ocorrido (Figura $2 \mathrm{~b}$ e Figura 3a).
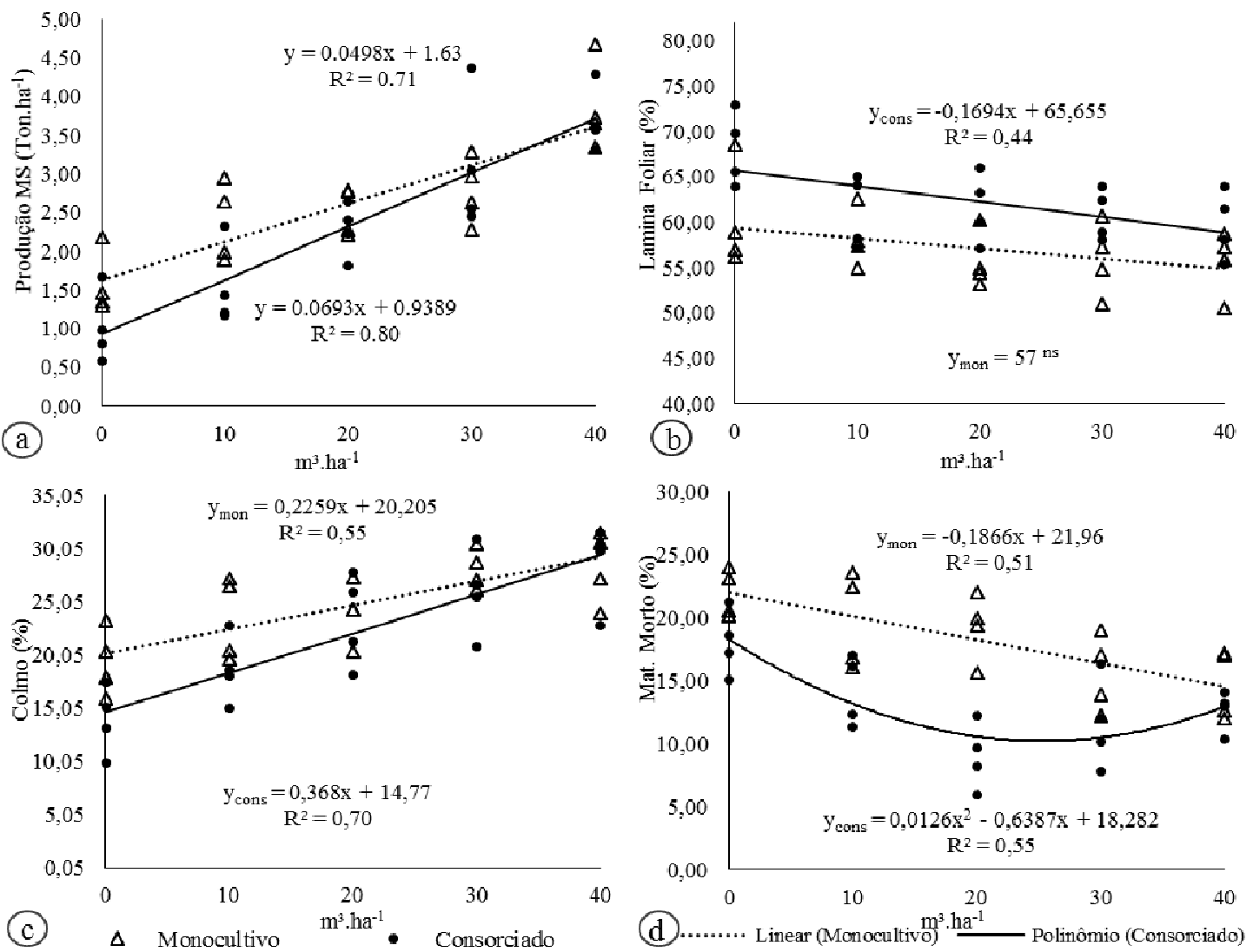

Figura 1. Produção de massa seca (a) e dos componentes folha (b), colmo (c) e material morto (d) do capim Piatã em função das doses de biofertilizante e dos sistemas de cultivo consorciado com sorgo forrageiro e monocultivo

Os maiores responsáveis pelo incremento produtivo do capim Piatã nos dois sistemas de produção com aplicação do biofertilizante, está correlacionado com a altura da pastagem, proporção de colmo e com número de perfilho (correlação $=0,53$; 0,82 e 0,65 respectivamente), sendo os principais responsáveis pelo aumento na produção de MST. No entanto foi observado correlação negativa entre produção de forragem com proporção de laminar foliar $(\mathrm{R}=-0,50)$ o que afeta a qualidade da forrageira, diminuição na participação de folhas na produção total de forragem compromete sua qualidade e eventual consumo dos animais (SARMENTO et al., 2010; MISTURA et 
Rev. Bras. Saúde Prod. Anim., Salvador, v.16, n.3, p.499-512 jul./set.., 2015 http://www.rbspa.ufba.br ISSN 15199940

al., 2007). O que torna importante conhecer as frações lamina foliar, colmo e material morto, pois traz informações importantes sobre a forma que a forragem está disponível para os animais.

A porcentagem de folhas do capim Piatã foi afetada de forma negativa com a aplicação de biofertilizante (Figura 1b), onde apresentou redução de $1,69 \%$ para cada $10 \mathrm{~m}^{3} \mathrm{ha}^{-1}$ de biofertilizante aplicado no sistema consorciado, não se ajustando $(\mathrm{P}>0,11)$ a nenhum modelo no sistema de monocultivo. Essa redução na participação de lamina foliar na MST está ligada diretamente com as características do biofertilizante e a quantidade por aplicação aplicada. Foram realizadas duas aplicações de biofertilizante aos 25 e aos 44 dias após a germinação, sendo evidenciado nas duas culturas cultivadas (Capim Piatã e Sorgo forrageiro) efeito fitotóxicos logo após sua aplicação, levando varias plantas a apresentarem clorose e necrose. $\mathrm{O}$ biofertilizante apresenta altas concentrações de cátions (Tabela 3) e microrganismo que aplicados em níveis elevados pode prejudica o desempenho produtivo (CAVALCANTE et al., 2007), afetando o processo de transporte de elétrons, ATP, translocação de água e nutrientes (LACERDA et al., 2007), e a alta carga de microrganismo aplicada no solo com os níveis maiores utilizados, compromete o sistema de defesa da planta afetando diretamente sua morfologia.

Houve diferença entre os sistemas de cultivos $\quad(\mathrm{P}<0,01) \quad$ apresentando participação de lamina foliar de $54 \%$ na pastagem em monocultivo e $64 \%$ em consórcio. A melhor resposta do capim Piatã no sistema consorciado está relacionado ao maior sombreamento ocorrido pelo consórcio com o sorgo, de forma compensatória a planta alonga folha para melhorar sua eficiência fotossintética, além disso, no consorciado a redução da chance de ocorrer contaminação por excesso de nutrientes do biofertilizante, por apresentar maior numero de plantas por área (Cultura do sorgo e capim Piatã).

Diferente da proporção de lamina foliar a aplicação do biofertilizante proporcionou aumento linear para proporção de colmo nos dois sistemas de cultivos (Figura 1c). Para cada $10 \mathrm{~m}^{3} \mathrm{ha}^{-1}$ de biofertilizante aplicado, houve incremento de $2,26 \%$ no monocultivo e 3,68\% na área em consórcio. Esse comportamento foi evidenciado por Araújo et al. (2011) utilizando resíduo liquido de bovino, obtiveram os mesmos comportamentos na morfologia da planta, com redução na participação de folhas e incremento na proporção de colmo com aplicação do resíduo em capim Marandu. Esse aumento na proporção de colmo reflete que o ponto de coleta da gramínea era afetado pelos tratamentos utilizados, o que é evidenciado pelo aumento na altura do dossel forrageiro. Possivelmente tenha ocorrido competição por luz, favorecendo o alongamento de colmo para facilitar captação de luz pelas folhas (SILVA et al., 2011).

O sistema consorciado apresentou menores proporções de material morto $(\mathrm{P}<0,04)$ que o sistema em monocultivo, apresentando redução de $27,77 \%$ com o consócio das culturas. No sistema de cultivo de lavoura e pasto consorciado propícia melhoria na retenção de água no solo e perda da umidade do solo, contribuindo para maior tempo de vida das folhas e dos perfilhos (MACEDO, 2009). Com a aplicação do biofertilizante as proporções de material senescido diminuíram $(\mathrm{P}<0,04)$, obtendo efeito linear, com redução média de 1,86\% para cada $10 \mathrm{~m}^{3} \mathrm{ha}^{-1}$ de biofertilizante aplicado no monocultivo, e apresentou efeito quadrático no sistema consorciado (Figura 1d), apresentando menor proporção de material morto com aplicação de $25,34 \mathrm{~m}^{3} \mathrm{ha}^{-1}$. 
Rev. Bras. Saúde Prod. Anim., Salvador, v.16, n.3, p.499-512 jul./set.., 2015 http://www.rbspa.ufba.br

A relação folha/colmo foi influenciado $(\mathrm{P}<0,01)$ de forma negativa com aplicação de biofertilizante (Figura 2a). O sistema que apresentou a melhor relação folha:colmo foi o consorciado, já as dozes de biofertilizante comprometeu a relação folha/colmo, isso devido ao maior crescimento das plantas e alongamento de colmo, uma vez que a relação folha/colmo apresentou correlação negativa com altura, proporção de colmo e massa por perfilho $(R=-0,69 ;-0,89$ e 0,76, respectivamente), além de apresentar correlação negativa com a produção total de MS $(\mathrm{R}=-0,71) \mathrm{e}$ número de perfilho $(\mathrm{R}=-0,35)$, mostrando que um dos grandes responsáveis pelo aumento produtivo está relacionado com aumento da participação de colmo. Com o aumento da massa de colmo, há o acréscimo na MST, no entanto esse incremento de produção afeta de forma negativa a qualidade da forragem e a estrutura do pasto.

Foi evidenciado interação $(\mathrm{P}<0,05)$ entre os sistemas de cultivos e as doses de biofertilizante para IAF, apresentando a partir de $30 \mathrm{~m}^{3} \mathrm{ha}^{-1}$ de biofertilizante aplicada melhor resposta para o sistema consorciado (Figura 2b). A resposta do biofertilizante apresentou efeito diferente nos sistemas de cultivos o que mostra que a interação do sistema de cultivo com o biofertilizante proporcionou nas maiores doses menor ação de fitotoxidade no sistema consorciado ajudando a minimizar os efeitos com o cultivo em conjunto das culturas.
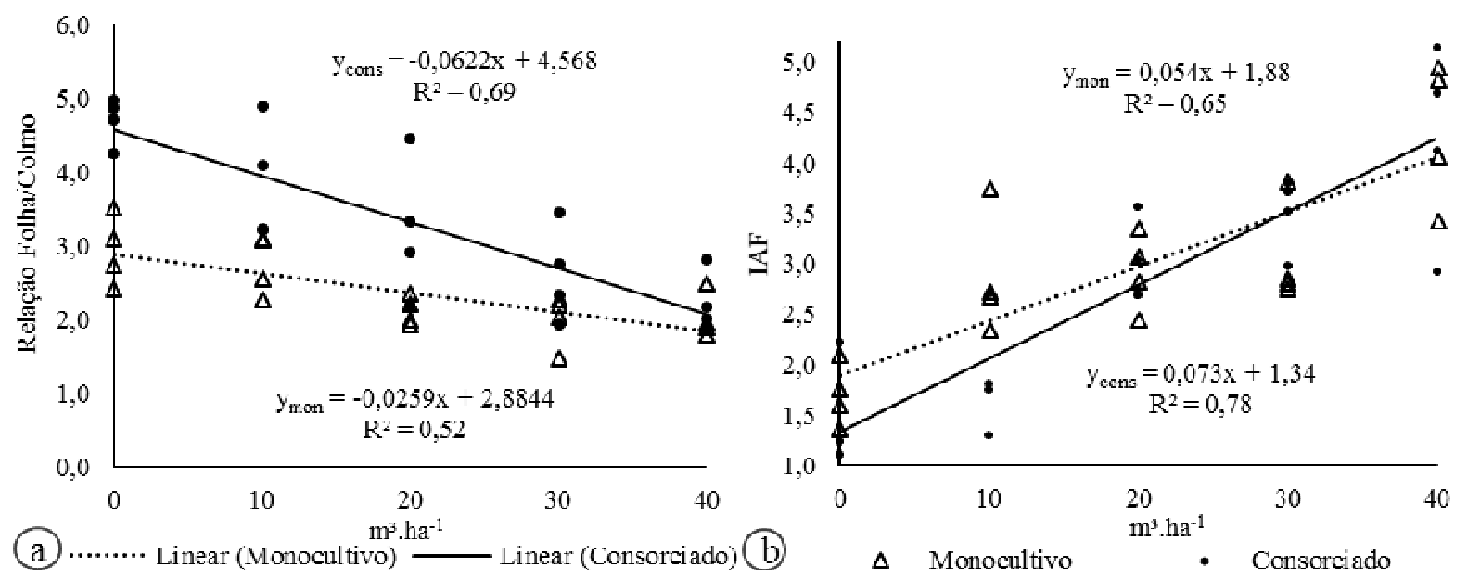

Figura 2. Relação folha/colmo (a) e IAF (b) do capim Piatã em função das doses de biofertilizante e dos sistemas de cultivo consorciado com sorgo forrageiro e monocultivo

Nos dois sistemas de cultivo as respostas adequaram-se ao modelo linear $(\mathrm{P}<0,01)$ com as doses de biofertilizante, apresentando para cada $10 \mathrm{~m}^{3} \mathrm{ha}^{-1}$ de biofertilizante aplicado, acréscimo de 0,54 e 0,73 no IAF no monocultivo e consorciado, respectivamente (Figura $2 b$ ). O IAF é diretamente influenciado pela intensidade de competição por luz entre as plantas (GIACOMINI et al., 2009), sendo no presente estudo o IAF influenciado pelo número de perfilho, onde apresentou alta correlação $(\mathrm{R}=0,98)$, não sendo diretamente ligado ao potencial fotossintético por perfilho em produzir maior número de folhas.

O efeito da aplicação do biofertilizante na altura do dossel do capim Piatã foi 
Rev. Bras. Saúde Prod. Anim., Salvador, v.16, n.3, p.499-512 jul./set.., 2015 http://www.rbspa.ufba.br ISSN 15199940

influenciado $(\mathrm{P}<0,01)$ de forma positiva, se ajustando ao modelo linear nos dois sistemas de cultivos (Figura $3 a)$. Com incremento de $3,74 \mathrm{~cm}$ e $4,54 \mathrm{~cm}$ para cada $10 \mathrm{~m}^{3} \mathrm{ha}^{-1}$ de biofertilizante aplicado no sistema de monocultivo e consorciado, respectivamente. Sendo considerado a altura ideal para manejo de pastejo do capim Piatã de 30 a $40 \mathrm{~cm}$ para obtenção de maior produção de forragem ao longo do ano (DIM et al., 2015), fato que mostra que nas maiores doses o capim estava superior ao ideal, evidenciando possível competição por luz entre os perfilhos.
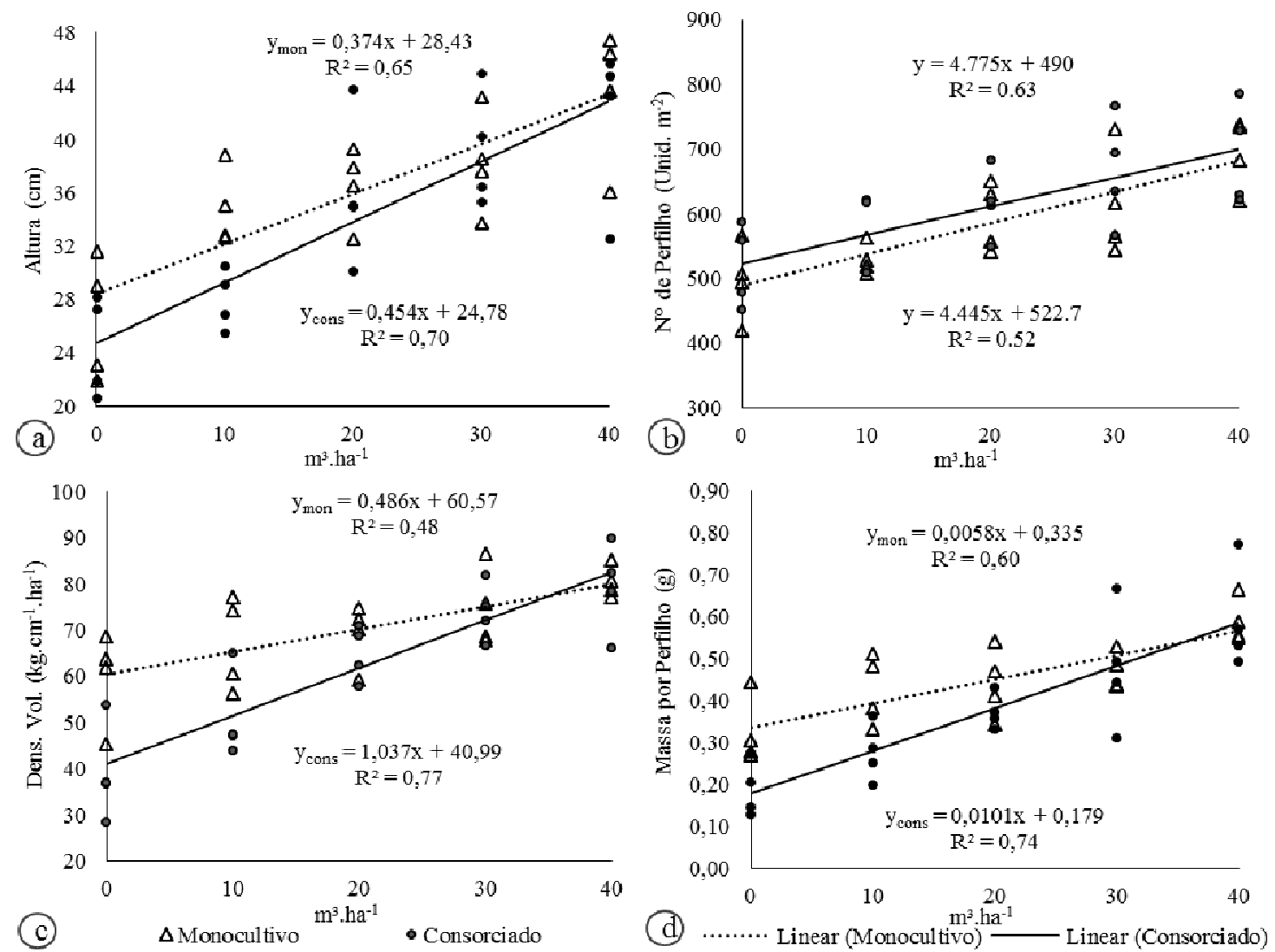

Figura 3. Altura (a), número de perfilho (b), densidade volumétrica (c) e massa por perfilho (d) do capim Piatã em função das doses de biofertilizante e dos sistemas cultivos consorciado com sorgo forrageiro e monocultivo

Com relação ao número de perfilho verificaram-se incrementos lineares $(\mathrm{P}<0,01)$ com o uso de biofertilizante no capim Piatã (Figura 3b), apresentando incremento de 47,75 e 44,45 perfilhos $\mathrm{m}^{-2}$ para cada $10 \mathrm{~m}^{3} \mathrm{ha}^{-1}$ de biofertilizante aplicado no monocultivo e no consórcio, respectivamente. A melhoria no perfilhamento com aplicação de biofertilizante comprova sua eficiência como fertilizante.
Assim como o número de perfilho, a massa por perfilho apresentou incrementos lineares $(\mathrm{P}<0,01)$ com $\mathrm{O}$ uso de biofertilizante no capim Piatã (Figura 3d). Apresentando massa semelhante nos dois sistemas de cultivo com aplicação de $40 \mathrm{~m}^{3} \mathrm{ha}^{-1}$ de biofertilizante $(0,59 \mathrm{~g}$ de MS). Um dos fatores que contribuiu para aumento do peso dos perfilhos é o aumento da altura do dossel (correlação de $\mathrm{R}=0,85$ ), que 
Rev. Bras. Saúde Prod. Anim., Salvador, v.16, n.3, p.499-512 jul./set.., 2015 http://www.rbspa.ufba.br ISSN 15199940

contribui para perfilhos mais compridos e mais pesados (SBRISSIA \& SILVA, 2008).

Para avaliar a eficiência biológica do sistema consorciado do sorgo com braquiária Piatã foi calculado o índice de equivalência de área (IEA) em comparação ao sistema de monocultivo das respectivas culturas. Quanto maior IEA, maior é a vantagem do sistema consorciado em relação ao sistema de monocultivo, no tratamento que recebeu $40 \mathrm{~m}^{3} \mathrm{ha}^{-1}$ de biofertilizante, o sistema consorciado apresentou IEA de 1,75, indicando que seria necessário $75 \%$ maior área de terra para o sistema de monocultivo apresentar a mesma produção que o sistema consorciado.

Foi verificado que em todas as doses testadas de biofertilizante o sistema consorciado apresentou superioridade, apresentando média de 58,5\% maior produção por área que em sistema de monocultivo (IEA $=1,53 ; 1,50 ; 1,56$; 1,75 para os tratamentos $10,20,30$ e 40 $\mathrm{m}^{3} \cdot \mathrm{ha}^{-1}$, respectivamente) o que mostra que o sistema consociado apresenta maior vantagem. A maior vantagem do sistema consorciado é em função da competição por área, devido a melhor utilização dos recursos naturais.

Alguns dos fatores que podem ter influenciado as variáveis agronômicas e estruturais podem ser explicados pelas características químicas do solo (Tabela 4 e 5). $\mathrm{O} \quad \mathrm{K}^{+}$apresentou interação $(\mathrm{P}<0,01)$ entre os sistemas de cultivos $\mathrm{e}$ as doses de biofertilizante na camada de 0-7 cm de profundidade, onde os maiores valores foram verificados no sistema de monocultivo média de $8,87 \mathrm{mg} \mathrm{dm}^{-3}$ e o sistema consorciado apresentou média de $4,57 \mathrm{mg} \mathrm{dm}^{-3}$. Onde o sistema consorciado apresentou redução de $48 \%$ nos teores de $\mathrm{K}^{+}$. Essas diferenças podem estar relacionadas pela exigência de ambas às culturas no sistema de consórcio, o que torna mais acelerado a extração dos nutrientes, já que no sistema consorciado não houve incremento nos teores de $\mathrm{K}^{+}$com aplicação de biofertilizante (Tabela 4). Outro fator que favorece a maior extração de $\mathrm{K}^{+}$é a relação que o $\mathrm{K}^{+}$tem com a quantidade de $\mathrm{N}$ disponível para plantas, tendo efeito linear com o aumento de $\mathrm{N}$ no solo (COSTA et al., 2010; PRIMAVESI et al., 2006).

A MO foi influenciada pelos sistemas de cultivos $(\mathrm{P}<0,01)$, apresentando o capim Piatã em monocultivo 48,28\% maior teor de MO que no sistema consorciado $\left(4,85 \mathrm{gdm}^{-3}\right.$ e $2,46 \mathrm{gdm}^{-3}$ sistema em monocultivo e consorciado, respectivamente). Os resultados divergem dos verificados por Schaefer et al. (2012), avaliando o teor de carbono orgânico no solo em sistema consorciado e em sistema de monocultivo, onde obtiveram maiores teores de carbono no sistema consorciado, isso pelo benefício das culturas envolventes em produzir maior biomassa. Os resultados divergentes dos verificados pelos autores provavelmente pela melhor retenção da umidade no sistema consorciado ter favorecido maior ação dos do biofertilizante, o que pode ter acelerado o processo de mineralização da matéria orgânica, favorecendo o processo de adsorção e absorção no solo e assim melhorando a ciclagem dos nutrientes.

Souza et al. (2014) avaliando a atividade microbiológica do solo após aplicação de dejetos líquidos de suínos em plantio de café, verificaram incremento superior a $144 \%$ na biomassa e na atividade microbiana após os 90 dias de aplicação do dejeto, em relação à testemunha (sem adição de dejetos líquidos de suínos). $\mathrm{O}$ $\mathrm{K}^{+}$e a $\mathrm{MO}$ apresentaram alta correlação $(\mathrm{R}=0,94)$, o que explica também a diminuição do $\mathrm{K}^{+}$com a mineralização da MO no sistema consorciado. 
Rev. Bras. Saúde Prod. Anim., Salvador, v.16, n.3, p.499-512 jul./set.., 2015 http://www.rbspa.ufba.br ISSN 15199940

Tabela 4. Características químicas do solo na camada de 0 a $7 \mathrm{~cm}$ de profundidade em função das doses de biofertilizantes e dos sistemas de cultivo consorciado e monocultivo

\begin{tabular}{|c|c|c|c|c|c|c|c|c|c|c|}
\hline \multirow{2}{*}{ Variáveis } & \multirow{2}{*}{ Sistema } & \multicolumn{5}{|c|}{ Doses de Biofertilizantes $\left(\mathrm{m}^{3} \mathrm{ha}^{-1}\right)$} & \multirow{2}{*}{ Média } & \multirow{2}{*}{\multicolumn{2}{|c|}{ Significância }} & \multirow{2}{*}{$\mathrm{CV}$} \\
\hline & & 0 & 10 & 20 & 30 & 40 & & & & \\
\hline \multirow{3}{*}{$\begin{array}{l}\mathrm{pH} \mathrm{em} \\
\mathrm{CaCl}_{2}\end{array}$} & Mon. & 5,50 & 6,03 & 6,17 & 5,87 & 6,05 & 5,92 & Inter. & 0,99 & \\
\hline & Cons. & 5,52 & 6,31 & 6,25 & 6,82 & 5,87 & 6,15 & Dos. & 0,49 & 13,9 \\
\hline & Média & 5,51 & 6,17 & 6,21 & 6,40 & 5,96 & - & Sist. & 0,86 & \\
\hline \multirow{3}{*}{$\begin{array}{l}\mathrm{Ca}(\mathrm{cmol} \\
\left.\mathrm{dm}^{-3}\right)\end{array}$} & Mon. & 3,05 & 3,16 & 3,17 & 2,54 & 4,58 & 3,30 & Inter. & 0,13 & \\
\hline & Cons. & 2,69 & 2,52 & 3,14 & 3,78 & 5,39 & 3,50 & Dos. & 0,01 & 22,8 \\
\hline & Média & $2,87^{\mathrm{c}}$ & $2,84^{\mathrm{c}}$ & $3,15^{b}$ & $3,16^{\mathrm{b}}$ & $4,98^{\mathrm{a}}$ & - & Sist. & 0,36 & \\
\hline \multirow{3}{*}{$\begin{array}{l}\mathrm{Mg}(\mathrm{cmol} \\
\left.\mathrm{dm}^{-3}\right)\end{array}$} & Mon. & 1,03 & 1,10 & 1,08 & 1,13 & 1,88 & 1,24 & Inter. & 0,12 & \\
\hline & Cons. & 1,28 & 1,31 & 1,09 & 0,89 & 0,48 & 1,01 & Dos. & 0,94 & 41,2 \\
\hline & Média & 1,16 & 1,21 & 1,09 & 1,01 & 1,18 & - & Sist. & 0,23 & \\
\hline \multirow{3}{*}{$\begin{array}{l}\mathrm{Al}(\mathrm{cmol} \\
\left.\mathrm{dm}^{-3}\right)\end{array}$} & Mon. & 0,23 & 0,18 & 0,14 & 0,17 & 0,20 & 0,18 & Inter. & 0,34 & \\
\hline & Cons. & 0,31 & 0,21 & 0,10 & 0,13 & 0,18 & 0,19 & Dos. & 0,01 & 32,9 \\
\hline & Média & $0,27^{\mathrm{a}}$ & $0,19^{\mathrm{a}}$ & $0,12^{\mathrm{b}}$ & $0,15^{\mathrm{b}}$ & $0,19^{\mathrm{a}}$ & - & Sist. & 0,87 & \\
\hline \multirow{3}{*}{$\mathrm{P}\left(\mathrm{mg} \mathrm{dm}^{-3}\right)$} & Mon. & 0,95 & 1,62 & 2,98 & 2,99 & 3,44 & 2,40 & Inter. & 0,10 & \\
\hline & Cons. & 1,10 & 1,78 & 2,30 & 2,19 & 4,01 & 2,28 & Dos. & 0,01 & 22,3 \\
\hline & Média & $1,02^{\mathrm{c}}$ & $1,70^{\mathrm{c}}$ & $2,64^{\mathrm{b}}$ & $2,59^{\mathrm{b}}$ & $3,72^{\mathrm{a}}$ & - & Sist. & 0,50 & \\
\hline \multirow{3}{*}{$\mathrm{K}\left(\mathrm{mg} \mathrm{dm} \mathrm{m}^{-3}\right)$} & Mon. & $2,00^{c}$ & $2,75^{\mathrm{c}}$ & $11,47^{\mathrm{ab}}$ & $11,89^{\mathrm{ab}}$ & $16,25^{\mathrm{a}}$ & 8,87 & Inter. & 0,01 & \\
\hline & Cons. & $2,00^{\mathrm{c}}$ & $3,50^{\mathrm{c}}$ & $4,00^{\mathrm{c}}$ & $6,00^{\mathrm{cb}}$ & $7,35^{\mathrm{cb}}$ & 4,57 & Dos. & 0,01 & 37,7 \\
\hline & Média & 2,00 & 3,12 & 7,73 & 8,94 & 11,80 & - & Sist. & 0,01 & \\
\hline \multirow{3}{*}{$\begin{array}{l}\mathrm{MO}\left(\mathrm{g} \mathrm{dm}^{-}\right. \\
3)\end{array}$} & Mon. & 1,94 & 3,11 & 3,52 & 6,27 & 9,41 & $4,85^{\mathrm{A}}$ & Inter. & 0,12 & \\
\hline & Cons. & 1,20 & 1,23 & 2,31 & 3,67 & 3,91 & $2,46^{\mathrm{B}}$ & Dos. & 0,01 & 43,1 \\
\hline & Média & $1,57^{\mathrm{c}}$ & $2,17^{\mathrm{c}}$ & $2,92^{\mathrm{bc}}$ & $4,97^{\mathrm{ab}}$ & $6,66^{\mathrm{a}}$ & - & Sist. & 0,01 & \\
\hline \multirow{3}{*}{$\begin{array}{l}\text { SB (cmol } \\
\left.\mathrm{dm}^{-3}\right)\end{array}$} & Mon. & 3,41 & 4,09 & 4,82 & 4,24 & 5,67 & 4,45 & Inter. & 0,41 & \\
\hline & Cons. & 3,98 & 3,56 & 4,08 & 4,69 & 5,04 & 4,27 & Dos. & 0,01 & 19,6 \\
\hline & Média & $3,69^{\mathrm{b}}$ & $3,82^{\mathrm{ab}}$ & $4,45^{\mathrm{ab}}$ & $4,46^{\mathrm{ab}}$ & $5,35^{\mathrm{a}}$ & - & Sist. & 0,52 & \\
\hline \multirow{3}{*}{$\begin{array}{l}\text { CTC ( }(\mathrm{cmol} \\
\left.\mathrm{dm}^{-3}\right)\end{array}$} & Mon. & 3,70 & 4,32 & 5,06 & 4,41 & 5,94 & 4,69 & Inter. & 0,38 & \\
\hline & Cons. & 4,24 & 3,74 & 4,22 & 4,82 & 5,18 & 4,44 & Dos. & 0,02 & 18,7 \\
\hline & Média & $3,97^{\mathrm{b}}$ & $4,03^{\mathrm{ab}}$ & $4,64^{\mathrm{ab}}$ & $4,61^{\mathrm{ab}}$ & $5,56^{\mathrm{a}}$ & - & Sist. & 0,39 & \\
\hline \multirow{3}{*}{ m (\%) } & Mon. & 7,92 & 3,77 & 3,22 & 4,03 & 3,57 & 4,50 & Inter. & 0,07 & \\
\hline & Cons. & 10,73 & 5,86 & 2,43 & 2,64 & 3,02 & 4,94 & Dos. & 0,01 & 33,7 \\
\hline & Média & $9,32^{\mathrm{a}}$ & $4,81^{\mathrm{b}}$ & $2,82^{\mathrm{b}}$ & $3,33^{\mathrm{b}}$ & $3,29^{\mathrm{b}}$ & - & Sist. & 0,47 & \\
\hline
\end{tabular}

$\mathrm{SB}=$ Soma de Bases; $\mathrm{MO}=$ Matéria orgânica; $\mathrm{CTC}_{\mathrm{e}}=$ Capacidade de troca catiônica efetiva; $\mathrm{m}=$ Saturação por alumínio; Significância pelo teste de F para Inter. = Interação; Dos. = Doses; Sist = Sistema. Médias seguidas de mesma letra não diferem entre si pelo teste de Tukey a 5\% probabilidade.

$\mathrm{O} \mathrm{Al}^{3+}$ trocável e saturação por alumínio apresentaram menores proporções $(\mathrm{P}<0,02)$ no sistema consorciado na profundidade de 7-15 $\mathrm{cm}$ de profundidade (Tabela 5), apresentando redução de $33,33 \%$ para $\mathrm{Al}^{3+}$ e $43,33 \%$ para saturação por alumínio em relação ao sistema de monocultivo. As menores concentrações provavelmente se devem ao processo de mineralização da matéria orgânica ter favorecido a precipitação do alumínio para camadas mais 
Rev. Bras. Saúde Prod. Anim., Salvador, v.16, n.3, p.499-512 jul./set.., 2015 http://www.rbspa.ufba.br ISSN 15199940

profundas, através da melhoria das concentrações das bases $\mathrm{Ca}^{2+}, \mathrm{Mg}^{2+} \mathrm{e}$ $\mathrm{K}^{+}$(NEVES NETO et al., 2012), sendo comprovado pela correlação negativa entre $\mathrm{Al}^{3+}$ e MO no sistema consorciado $(\mathrm{R}=-0,59)$. Outro fator que podem ter contribuído é a complexação do $\mathrm{Al}^{3+}$ com ânions orgânicos, não sendo mensurados na extração com $\mathrm{KCl}$ a $1 \mathrm{~mol} \mathrm{dm}{ }^{-3}$ (AMARAL et al., 2000; CERETTA et al., 2003).

Tabela 5. Características químicas do solo na camada de 7 a $15 \mathrm{~cm}$ de profundidade em função das doses de biofertilizantes e dos sistemas de cultivo consorciado e monocultivo

\begin{tabular}{|c|c|c|c|c|c|c|c|c|c|c|}
\hline \multirow{2}{*}{ Variáveis } & \multirow{2}{*}{ Sistema } & \multicolumn{5}{|c|}{ Doses de Biofertilizantes $\left(\mathrm{m}^{3} \mathrm{ha}^{-1}\right)$} & \multirow{2}{*}{ Média } & \multirow{2}{*}{\multicolumn{2}{|c|}{ Significância }} & \multirow{2}{*}{$\mathrm{CV}$} \\
\hline & & 0 & 10 & 20 & 30 & 40 & & & & \\
\hline \multirow{3}{*}{$\begin{array}{l}\mathrm{pH} \mathrm{em} \\
\mathrm{CaCl}_{2}\end{array}$} & Mon. & 6,00 & 6,07 & 5,51 & 6,28 & 5,83 & 5,94 & Inter. & 0,06 & \\
\hline & Cons. & 4,71 & 6,59 & 6,37 & 5,47 & 5,10 & 5,65 & Dos. & 0,11 & 11,2 \\
\hline & Média & 5,36 & 6,33 & 5,94 & 5,88 & 5,47 & - & Sist. & 0,20 & \\
\hline \multirow{3}{*}{$\begin{array}{l}\mathrm{Ca}(\mathrm{cmol} \\
\left.\mathrm{dm}^{-3}\right)\end{array}$} & Mon. & 2,53 & 2,53 & 1,56 & 2,61 & 2,38 & 2,32 & Inter. & 0,06 & \\
\hline & Cons. & 2,01 & 2,04 & 2,46 & 2,11 & 2,19 & 2,16 & Dos. & 0,67 & 21,5 \\
\hline & Média & 2,27 & 2,29 & 2,01 & 2,36 & 2,29 & - & Sist. & 0,35 & \\
\hline \multirow{3}{*}{$\begin{array}{l}\mathrm{Mg}(\mathrm{cmol} \\
\left.\mathrm{dm}^{-3}\right)\end{array}$} & Mon. & 0,92 & 1,14 & 1,52 & 1,66 & 1,23 & 1,29 & Inter. & 0,06 & \\
\hline & Cons. & 1,72 & 0,55 & 1,37 & 1,61 & 1,42 & 1,33 & Dos. & 0,01 & 17,7 \\
\hline & Média & $1,32^{\mathrm{a}}$ & $0,85^{\mathrm{b}}$ & $1,44^{\mathrm{a}}$ & $1,63^{\mathrm{a}}$ & $1,32^{\mathrm{a}}$ & - & Sist. & 0,13 & \\
\hline \multirow{3}{*}{$\begin{array}{l}\mathrm{Al}(\mathrm{cmol} \\
\left.\mathrm{dm}^{-3}\right)\end{array}$} & Mon. & 0,19 & 0,26 & 0,21 & 0,16 & 0,20 & $0,21^{\mathrm{A}}$ & Inter. & 0,36 & \\
\hline & Cons. & 0,17 & 0,09 & 0,16 & 0,15 & 0,11 & $0,14^{\mathrm{B}}$ & Dos. & 0,92 & 36 \\
\hline & Média & 0,18 & 0,18 & 0,19 & 0,16 & 0,16 & - & Sist. & 0,02 & \\
\hline \multirow{3}{*}{$\mathrm{P}\left(\mathrm{mg} \mathrm{dm}^{-3}\right)$} & Mon. & 0,94 & 1,29 & 1,32 & 1,62 & 2,12 & 1,46 & Inter. & 0,58 & \\
\hline & Cons. & 0,96 & 1,36 & 1,11 & 1,88 & 2,62 & 1,59 & Dos. & 0,01 & 27,7 \\
\hline & Média & $0,95^{\mathrm{c}}$ & $1,32^{\mathrm{bc}}$ & $1,22^{\mathrm{bc}}$ & $1,75^{\mathrm{ab}}$ & $2,37^{\mathrm{a}}$ & - & Sist. & 0,39 & \\
\hline \multirow{3}{*}{$\mathrm{K}\left(\mathrm{mg} \mathrm{dm}^{-3}\right)$} & Mon. & 1,75 & 2,64 & 2,87 & 6,71 & 7,00 & 4,19 & Inter. & 0,23 & \\
\hline & Cons. & 1,00 & 1,28 & 3,12 & 3,00 & 8,46 & 3,37 & Dos. & 0,01 & 44,3 \\
\hline & Média & $1,38^{\mathrm{c}}$ & $1,96^{\mathrm{c}}$ & $3,00^{\mathrm{b}}$ & $4,86^{\mathrm{ab}}$ & $7,73^{\mathrm{a}}$ & - & Sist. & 0,16 & \\
\hline \multirow{3}{*}{$\begin{array}{l}\text { M.O }\left(\mathrm{g} \mathrm{dm}^{-}\right. \\
\left.{ }^{-}\right)\end{array}$} & Mon. & 1,81 & 0,74 & 2,95 & 2,97 & 5,43 & 2,78 & Inter. & 0,38 & \\
\hline & Cons. & 2,09 & 1,81 & 1,55 & 3,59 & 3,32 & 2,47 & Dos. & 0,03 & 49,2 \\
\hline & Média & $1,95^{\mathrm{b}}$ & $1,28^{\mathrm{b}}$ & $2,25^{\mathrm{ab}}$ & $3,28^{\mathrm{ab}}$ & $4,38^{\mathrm{a}}$ & - & Sist. & 0,65 & \\
\hline \multirow{3}{*}{$\begin{array}{l}\text { SB }(\mathrm{cmol} \\
\left.\mathrm{dm}^{-3}\right)\end{array}$} & Mon. & 3,36 & 3,92 & 2,94 & 4,63 & 4,12 & 3,79 & Inter. & 0,08 & \\
\hline & Cons. & 3,90 & 2,69 & 3,42 & 3,35 & 3,44 & 3,36 & Dos. & 0,01 & 13,8 \\
\hline & Média & $3,63^{\mathrm{ab}}$ & $3,31^{\mathrm{ab}}$ & $3,18^{\mathrm{b}}$ & $3,99^{\mathrm{a}}$ & $3,78^{\mathrm{ab}}$ & - & Sist. & 0,22 & \\
\hline \multirow{3}{*}{$\begin{array}{l}\text { CTC (cmol } \\
\left.\mathrm{dm}^{-3}\right)\end{array}$} & Mon. & 3,55 & 4,13 & 3,12 & 4,85 & 4,35 & 4,00 & Inter. & 0,07 & \\
\hline & Cons. & 4,11 & 3,23 & 3,64 & 3,69 & 4,67 & 3,87 & Dos. & 0,02 & 15,1 \\
\hline & Média & $3,83^{\mathrm{ab}}$ & $3,68^{\mathrm{ab}}$ & $3,38^{\mathrm{b}}$ & $4,27^{\mathrm{ab}}$ & $4,51^{\mathrm{a}}$ & - & Sist. & 0,50 & \\
\hline \multirow{3}{*}{$\mathrm{m}(\%)$} & Cons. & 4,38 & 1,80 & 4,19 & 4,00 & 2,64 & $3,40^{\mathrm{B}}$ & Inter. & 0,09 & \\
\hline & Mon. & 7,06 & 6,77 & 6,69 & 3,95 & 5,52 & $6,00^{\mathrm{A}}$ & Dos. & 0,20 & 27,5 \\
\hline & Média & 5,72 & 4,29 & 5,44 & 3,98 & 4,08 & - & Sist. & 0,01 & \\
\hline
\end{tabular}

$\mathrm{SB}=$ Soma de Bases; $\mathrm{MO}=$ Matéria orgânica; $\mathrm{CTC}_{\mathrm{e}}=$ Capacidade de troca catiônica efetiva; $\mathrm{m}=$ Saturação por alumínio; Significância pelo teste de F para Inter. = Interação; Dos. = Doses; Sist = Sistema. Médias seguidas de mesma letra não diferem entre si pelo teste de Tukey a 5\% probabilidade. 
Rev. Bras. Saúde Prod. Anim., Salvador, v.16, n.3, p.499-512 jul./set.., 2015 http://www.rbspa.ufba.br

A aplicação do biofertilizante proporcionou aumento nos teores de $\mathrm{Ca}^{2+}$ trocável e $\mathrm{P}$ disponível no solo na camada de $0-7 \mathrm{~cm}$ de profundidade (Tabela 4). Sendo as melhores respostas de $\mathrm{Ca}^{2+}$ e $\mathrm{P}$ obtidas com aplicação de $40 \mathrm{~m}^{3} \mathrm{ha}^{-1}$ de biofertilizante $\left(4,98\right.$ e $3,72 \mathrm{cmol}_{\mathrm{c} .} \mathrm{dm}^{-3}$ para $\mathrm{Ca}^{2+}$ e P, respectivamente), apresentando acréscimo de $42,37 \%$ nos teores de $\mathrm{Ca}^{2+} \mathrm{e}$ de $72,58 \%$ nos teores de $\mathrm{P}$ em relação à testemunha. O mesmo foi observado por Ceretta et al. (2003) que obteve acréscimo nos teores de $\mathrm{Ca}$ e $\mathrm{P}$ de forma crescente com aplicação de estercos líquidos de suínos até a dose de $40 \mathrm{~m}^{3} \mathrm{ha}^{-}$ 1 em áreas de pastagem natural. Verificaram também que houve migração do $\mathrm{P}$ para camadas mais profundas com aplicação de maiores doses de estercos líquidos de suínos. $\mathrm{O}$ que foi evidenciado neste trabalho, já que houve respostas crescentes com aplicação das doses de biofertilizante na cama de $7-15 \mathrm{~cm}$ de profundidade para $\mathrm{P}, \mathrm{K}^{+}, \mathrm{MO}, \mathrm{SB}, \mathrm{CTC}_{\mathrm{e}}$ (Tabela 4 e 5).

A SB e a CTC efetiva do solo foram afetadas $(\mathrm{P}<0,02)$ pelas doses de biofertilizantes nas duas profundidades avaliadas (Tabela 4 e 5). Apresentando os melhores resultados na camada superficial $0-7 \mathrm{~cm}$, cerca de $17,98 \%$ e $13,78 \%$ maior SB e CTC efetiva, respectivamente na camada de $0-7 \mathrm{~cm}$ em relação à camada $7-15 \mathrm{~cm}$ de profundidade. Apresentando as melhores concentrações com aplicação de $40 \mathrm{~m}^{3} \mathrm{ha}^{-1}$ de biofertilizante na camada de $0-7 \mathrm{~cm}$ de profundidade e na cama de $7-15 \mathrm{~cm}$ de profundidade a maior dose de biofertilizante não se diferenciou da testemunha (Tabela 4 e 5). O que mostra que houve absorção dos nutrientes pelas plantas, uma vez que com as aplicações de biofertilizante $o$ incremento na produção foi 2,65 vezes maior com aplicação de $40 \mathrm{~m}^{3} \mathrm{ha}^{-1}$ em comparação à testemunha.
Com base no exposto conclui-se que a adubação com biofertilizante proporcionou incrementos na produção do capim Piatã, podendo o biofertilizante ser utilizado como fonte de adubação até a dose de $40 \mathrm{~m}^{3} \mathrm{ha}^{-1} \mathrm{em}$ Neossolo Quartzarênico órtico típico.O sistema consorciado de capim Piatã com sorgo forrageiro mostrou ser mais eficiente quanto ao uso dos recursos apresentando maior produtividade por áreas das duas culturas evolvidas que em sistema de monocultivo. A utilização de biofertilizantes proporcionou melhorias nas características químicas do solo. No entanto, deve-se realizar mais pesquisas com uso de biofertilizantes testando maiores doses e maiores números de aplicações para verificar as respostas das culturas sem causar efeito fitotóxicos, bem como para estimar a capacidade do solo em absorver os nutrientes presente no biofertilizante, sem causar impactos ambientais.

\section{REFERÊNCIAS}

AMARAL, A.S.; SPADER, V.; ANGHINONI, I.; MEURER, E.J. Resíduos vegetais na superfície do solo afetam a acidez do solo e a eficiência do herbicida flumetsulam. Ciência Rural, v.30, n.5, p.789-794, 2000.

ARAÚJO, J.F.; LEONEL, S.; PEREIRA NETO, J. Adubação organomineral e biofertilização líquida na produção de frutos de pinheira (Annona squamosal L.) no submédio São Francisco, Brasil. Bioscience Journal, v.24, n.4, p.48-57, 2008.

ARAÚJO, A.S.; SANTOS, A.C.; SILVA NETO, S.P.; SANTOS, P.M.; SILVA, J.E.C.; SANTOS, J.G.D. Produtividade do capim-marandu e 
Rev. Bras. Saúde Prod. Anim., Salvador, v.16, n.3, p.499-512 jul./set.., 2015 http://www.rbspa.ufba.br ISSN 15199940

alterações químicas do solo submetido a doses de dejetos líquidos de bovinos.

Revista de Ciências Agrarias, v.54, n.3, p.235-246, 2011.

BALBINO, L.C.; CORDEIRO, L.A.; PORFÍRIO-DA-SILVA, V.; MORAES, A.; MARTÍNEZ, G.B.; ALVARENGA, R.C.; KICHEL, A.N.; FONTANELI, R.S.; SANTOS, H.P.; FRANCHINI, J.C.; GALERANI, P.G. Evolução tecnológica e arranjos produtivos de sistemas de integração lavourapecuária-floresta no Brasil. Pesquisa Agropecuária Brasileira, v.46, n.10, p. i-xii, 2011.

CAVALCANTE, L.F.; SANTOS, G.D.; OLIVEIRA, F.A.; CAVALCANTE, I.H.L.; GONDIM, S.C.;

CAVALCANTE, M.Z.B. Crescimento e produção do maracujazeiro-amarelo em solo de baixa fertilidade tratado com biofertilizantes líquidos. Revista Brasileira de Ciências Agrárias, v.2, n.1, p.15-19, 2007.

CERETTA, C.A.; DURIGON, R.; BASSO, C.J.; BARCELLOS, L.A.R.; VIEIRA, F.C.B. Características químicas de solo sob aplicação de esterco líquido de suínos em pastagem natural. Pesquisa agropecuária brasileira, v.38, n.6, p.729-735, 2003.

COSTA, K.A.P.; OLIVEIRA, I.P.; SEVERIANO, E.C.; SAMPAIO, F.M.T.; CARRIJO, M.S.; RODRIGUES, C.R. Extração de nutrientes pela fitomassa de cultivares de Brachiaria brizantha sob doses de nitrogênio. Ciência Animal Brasileira, v.11, n.2, p.307-314, 2010.

DIM, V.P.; ALEXANDRINO, E.; SANTOS, A.C.; MENDES, R.S.; SILVA, D.P. Características agronômicas, estruturais e bromatológicas do capim Piatã em lotação intermitente com período de descanso variável em função da altura do pasto. Revista Brasileira de Saúde e Produção Animal [online], v.16, n.1, p.10-22, 2015.

GIACOMINI, A.A.; SILVA, S.C; SARMENTO, D.O.L; ZEFERINO, V; TRINDADE, J.K; SOUZA JÚNIOR, S.J; GUARDA, V.D; SBRISSIA, A.F; NASCIMENTO JÚNIOR, D.

Components of the leaf area index of marandu palisadegrass swards subjected to strategies of intermittent stocking.

Scientia Agricola, v.66, n.6, p.721-732, 2009.

LACERDA, C.F.; ENÉAS FILHO, J.; PINHEIRO, C.B. Fisiologia Vegetal: capitulo nutrição mineral. Fortaleza, CE: Universidade Federal do Ceará, 2007.

MACEDO, M.C.M. Integração lavoura e pecuária: o estado da arte e inovações tecnológicas. Revista Brasileira de Zootecnia, v.38, p.133-146, 2009.

MISTURA, C.; FONSECA, D.M.; MOREIRA, L.M.; FAGUNDES, J.L.; MORAIS, R.V.; QUEIROZ, A.C.; RIBEIRO JÚNIOR, J.I. Efeito da adubação nitrogenada e irrigação sobre a composição químico-bromatológica das lâminas foliares e da planta inteira de capim-elefante sob pastejo. Revista Brasileira Zootecnia, v.36, n.6, p.1707-1714. 2007.

NEVES NETO, D.N.; SANTOS, A.C.; SILVA NETO, S.P. Atributos físicos e químicos do solo em ecossistema de capim-Mombaça na Amazônia Oriental. Revista de Ciências Agrárias, v.55, n. 2, p. $75-84,2012$. 
Rev. Bras. Saúde Prod. Anim., Salvador, v.16, n.3, p.499-512 jul./set.., 2015 http://www.rbspa.ufba.br

PARIZ, C.M.; ANDREOTTI, M.;

TARSITANO, A.A.;

BERGAMASCHINE, A.F.;

BUZETTI, S.; CHIODEROLI, C.A.

Desempenhos técnicos e econômicos

da consorciação de milho com

forrageiras dos gêneros Panicum e

Brachiaria em sistema de integração

lavoura-pecuária. Pesquisa

Agropecuária Tropical, v.39, n.4, p.360-370, 2009.

PRIMAVESI, A.C.; PRIMAVESI, O.; CORREAA, L.A.; SILVA, A.G.;

CANTARELLA, H. Nutrientes na

fitomassa de capim-marandu em função de fontes e doses de nitrogênio.

Ciência e Agrotecnologia, v.30, n.3, p.562-568, 2006.

SARMENTO, C.M.B.; VEIGA, J.B.; RISCHKOWSKY, B.; KATO, O.R.; SIEGMUND-SCHULTZE, $M$.

Caracterização e avaliação da pastagem do rebanho de agricultores familiares do nordeste paraense. Acta Amazônica, v.40, n.3, p.415-423, 2010 .

SBRISSIA, A.F.; DA SILVA, S.C. Compensação tamanho/densidade populacional de perfilhos em pastos de capim-marandu. Revista Brasileira de Zootecnia, v.37, n.1, p.35-47, 2008.

SCHAEFER, P.E.; PIZZANI, R.; LOVATO, T.; LUDWIG, R.L.; GOULART, R.G. Atributos físicos e carbono orgânico do solo em sistemas forrageiros em cultivo singular ou em consórcio. Enciclopédia Biosfera, v.8, n.14, p.97-104, 2012.
SILVA, T.C.; MACEDO, C.H.O.; ARAUJO, S.S.; PINHO, R.M.A.; PERAZZO, A.F.; SANTOS, E.M.; GONZAGA NETO, S. Características agronômicas do capim Brachiaria decumbens submetido a intensidades e frequências de corte e adubação nitrogenada. Revista Brasileira de Saúde e Produção Animal [online], v.12, n.3, p.583 593, 2011.

SOUSA, F.A.; SILVA, E.B.; CAMPOS, A.T.; GANDINI, A.M.M.; CORRÊA, J.M.; GRAZZIOTTI, P.H. Atividade microbiana e produção da lavoura cafeeira após adubação com dejetos líquidos de suínos. Bioscience Journal, n.4, v.30, p. 1041-1049, 2014.

Data de recebimento: 04/08/2014

Data de aprovação: 08/09/2015 